Hope College

Hope College Digital Commons

Faculty Publications

$5-1-2019$

\title{
Steadfast Standards or Fluctuating Fancies? Stability and Change in People's Mate Criteria Over 27 Months
}

\author{
Carrie A. Bredow \\ Hope College, bredow@hope.edu \\ Nicole Hames \\ Hope College
}

Follow this and additional works at: https://digitalcommons.hope.edu/faculty_publications

Part of the Personality and Social Contexts Commons, and the Social Psychology Commons

\section{Recommended Citation}

Repository citation: Bredow, Carrie A. and Hames, Nicole, "Steadfast Standards or Fluctuating Fancies? Stability and Change in People's Mate Criteria Over 27 Months" (2019). Faculty Publications. Paper 1477. https://digitalcommons.hope.edu/faculty_publications/1477

Published in: Personality and Social Psychology Bulletin, Volume 45, Issue 5, May 1, 2019, pages 671-687. Copyright @ 2019 Sage.

This Article is brought to you for free and open access by Hope College Digital Commons. It has been accepted for inclusion in Faculty Publications by an authorized administrator of Hope College Digital Commons. For more information, please contact digitalcommons@hope.edu. 
Steadfast Standards or Fluctuating Fancies?

Stability and Change in People's Mate Criteria Over 27 Months

Carrie A. Bredow \& Nicole Hames

Hope College

Please direct correspondence to:

Carrie Bredow

Hope College

Department of Psychology

P.O. Box 9000

Holland, MI 49422

Phone: 616-395-7254

email: bredow@hope.edu 


\begin{abstract}
Although research on mate preferences has been built on the assumption that the criteria people report at one point in time should predict their future partnering behavior, little is known about the temporal stability of people's standards. Using survey data collected at four time points from 285 originally unmarried individuals, this study examined the rank-order, mean-level, individuallevel and ipsative stability of people's mate criteria over 27 months. Overall, reported standards exhibited moderate to high baseline stability, with rank-order and ipsative estimates comparable to those reported for personality traits. At the same time, mean- and individual-level analyses revealed small, but significant, increases in participants' reported criteria over the study, as well as significant variability in individual trajectories. Consistent with theory, the stability of individuals' standards was moderated by several contextual factors, including age, changes in perceived mate value, and significant relationship events.
\end{abstract}

Keywords: Mate preferences; mate selection; stability; mate value; relationships 
Steadfast Standards or Fluctuating Fancies? Stability and Change in People's

\section{Mate Criteria Over 27 Months}

As relationship science has blossomed over the last 75 years, social scientists have enjoyed a steadfast love affair with the study of people's preferences for a romantic partner. Although the nature of the infatuation has evolved - progressing from Hill's (1945) descriptive explorations to the more sophisticated theoretical and statistical designs of recent work (ConroyBeam \& Buss, 2016; Eastwick, Luchies, Finkel, \& Hunt, 2014) - the underlying presumption that mate preferences play a central role in romantic partnering has been consistent. However, despite abundant research examining the content of people's mate criteria, remarkably little is known about the process through which these preferences influence later relationship cognitions and behaviors. We know what Sandra says she wants - and have a priori predictions for why she should want it - but we understand little about what happens next. If Sandra reports valuing physical attractiveness more than others at Time 1, is this preference reflected in her partner choice and relationship evaluations at Time 2? And, if not, what went wrong?

In recent years, researchers have taken significant strides toward answering these questions and challenging previously unchecked beliefs in mate preferences' predictive power. Stymied by Eastwick and Finkel's (2008) discovery that the preferences people reported prior to speed-dating failed to predict who they were attracted to at the event itself, researchers have begun to examine whether, when, and how reported mate criteria actually influence partnering attitudes and behaviors. These investigations have been fruitful in many ways, demonstrating that reported mate preferences can and do predict romantic interest and behavior under the correct conditions (e.g., Fletcher, Kerr, Li, \& Valentine, 2014; Li et al., 2013). But notably, most of this work has dealt with the functioning of mate preferences in the very early stages of mate 
selection and at a single point in time. In contrast, only a handful of studies have examined how mate preferences reported at one point in time predict later partnering outcomes (e.g., Eastwick, Finkel, \& Eagly, 2011; Eastwick \& Neff, 2012), and the results have been equivocal. Indeed, in two separate studies of mate preferences' predictive validity over 27 and 36 months (Eastwick et al., 2011; Eastwick \& Neff, 2012), only a match in the pattern of people's standards relative to their partner's traits predicted relationship outcomes; the actual level of a trait possessed by one's partner did not seem to matter. In both studies, the degree of correspondence between people's stated preference for a trait and the level of that trait possessed by their partner was entirely unrelated to their relational outcomes.

Although a variety of explanations have been posited to account for mate preferences' inconsistent predictive validity - including the possibility that variability in the level of people's reported criteria is simply not meaningful (e.g., Eastwick et al., 2014; Eastwick \& Neff, 2012) one variable that has received surprisingly little attention is mate standards' temporal stability. The ability of stated mate preferences to predict future, as opposed to only concurrent, partnering attitudes and behaviors is contingent on mate standards exhibiting reasonable stability over time. But is this a tenable assumption? Does a person's set of previously reported mate preferences closely parallel the criteria he or she uses when evaluating a romantic partner two years later? Or do shifting contexts and the passage of time produce enough normative change in standards to minimize their predictive utility? Despite the importance of these questions to understanding standards' downstream effects, only a few studies have assessed people's mate preferences at more than one point in time (e.g., Eastwick \& Finkel, 2008; Fletcher et al., 2000) and none of this work was designed to investigate continuity in stated criteria. Using four waves of data 
collected over 27 months, our research addresses this deficit by providing the first systematic analysis of stability and change in people's mate standards as partnering processes unfold.

\section{Continuity vs. Change in Mate Standards}

Are mate standards stable factors rooted in people and their traits or fluctuating fancies that adventitiously mold themselves to whatever partnering opportunities arise? Although most prominent theories of mate selection lean toward the former, theoretical forecasts of mate standards' temporal stability are less straightforward than the methodology of prospective studies would imply. According to evolutionary theory, for instance, people's mating choices are driven by psychological mechanisms that evolved over millennia, in the form of mate preferences, to help our ancestors solve adaptive problems related to survival and reproduction (Buss; 2003; Cosmides \& Tooby, 1992). Because such adaptations take thousands of years to occur, our present-day preferences are thought to primarily reflect selection pressures from our reproductive histories rather than modern partnering circumstances or adventitious whims. But this does not suggest that people's mate criteria should be rigid or impervious to current environmental cues. On the contrary, a key tenet of the evolutionary perspective is that contextual factors play a critical role in determining what mating strategies - and, thus, what mate preferences - are most advantageous at any given time (e.g., Gangestad, Haselton, \& Buss, 2006; Stone, Shackelford, \& Buss, 2007). Thus, despite characterizing mate preferences as psychological adaptations that logically guide partnering behaviors, evolutionary theorists do not assume these preferences will be static and suggest several circumstances (e.g., changes in the availability of potential partners or one's own mate value) in which shifting standards may be expected.

Interdependence theory also conceptualizes mate preferences as reasonably flexible knowledge structures that play a critical role in partnering. According to interdependence 
theory, people's mate standards serve an important regulatory function in partnering by providing them with a baseline against which their romantic experiences can be compared and evaluated (Thibaut \& Kelley, 1959). One popular derivation of this theory - the Ideal Standards Model (ISM) - characterizes mate preferences as stable in structure, but varying with respect to their accessibility and centrality in different relationship contexts (Fletcher, Simpson, Thomas, \& Giles, 1999). In other words, although mate standards are expected to maintain a stable, threefactor structure over time (i.e., attractiveness/vitality, status/resources, warmth/trustworthiness), the salience and importance of these criteria are projected to shift as relationships progress and enhancement versus accuracy motives are activated (Campbell, Simpson, Kashy, \& Fletcher, 2001; Fletcher et al., 2000).

In sum, both evolutionary and social psychological models of mate selection suggest that mate preferences cannot necessarily be treated as immutable predictors. But the empirical implications of this theoretical supposition are unclear. Are most adjustments to people's standards infrequent and subtle, such that the average individual's criteria are reasonably consistent over time? Or are marked shifts in people's mate preferences quite common, resulting in low baseline stability, and - by extension - attenuated utility for predicting and explaining future behavior? Although the failure of stated preferences to predict certain behaviors has often been interpreted as an indictment of the underlying theoretical accounts (e.g., Eastwick et al., 2014), an absence of clear downstream effects could just as easily reflect our poor understanding of how partnering processes unfold. Without knowing how much change is normative, when adjustments in criteria are most likely, and whether time and context affect all preference metrics (e.g., level vs. pattern) equally, it is hard to know how to interpret existing research on mate 
standards' prospective validity or to discern what (if any) aspects of the underlying theories are “in need of revision” (Eastwick et al., 2014, p. 25).

To the best of our knowledge, only six studies have assessed the mate preferences of a single sample at more than one point in time and reported the associations among the measures. When examining the test-retest reliability of the ISM over a three-week period, Fletcher and colleagues (1999) found T1-T2 preference correlations of .86 for vitality/attractiveness traits, .85 for status/resources traits, and .75 for warmth/trustworthiness traits. In a second study assessing college students at the beginning of their relationships and again two months later, correlations were .64 for vitality/attractiveness, .82 for status/resources, and .78 for warmth/loyalty (Fletcher et al., 2000). Eastwick and Finkel (2008), who measured students' preferences prior to a speeddating event and one month later, also reported highly significant correlations (.68 for physical attractiveness, .60 for earning prospects, and .52 for personable), as did Gerlach and colleagues (2017) in a study assessing the preferences of originally single adults twice over five months (.69 for vitality-attractiveness, .73 for status-resources, and .56 for warmth-trustworthiness). Overall, these studies suggest that reported mate preferences exhibit reasonably high baseline stability over short periods of time.

Less can be said about the stability of people's mate preferences over longer durations. In one relevant investigation, Zentner (2005) assessed dating individuals' ideal mate personality concepts using a Q-sort task at the beginning of the study and again nine months later. Computing within-person correlations between the two sets of rankings revealed a median profile correlation of .72, reflecting "trait-like" stability. Aside from this work, only one other study has investigated changes in reported mate criteria over more than a few months. Using data from 27 couples who responded to a three-year follow-up, Shackelford, Schmitt, and Buss 
(2005) examined the stability of couples' mate preferences between their first and fourth year of marriage and found correlations ranging from .16 to .82 for women (median $r=.47$ ) and .21 to .69 for men (median $r=.51$ ). Unfortunately, the limited power of this data temper its contribution to understanding mate preferences' long-term stability.

Given the limited scope of the work described in the preceding paragraphs, the first objective of our study was to provide a methodologically rigorous account of continuity and change in people's standards over almost two-and-a-half years. In addition to tracking the continuity of people's standards over a much longer period than past studies (using twice as many points of assessment), we remedied the limited power and generalizability of previous work by recruiting a large, mostly non-collegiate sample of both partnered and unpartnered adults. Moreover, because estimates of temporal stability are often intricately tied to how stability is measured (Roberts, Caspi, \& Moffitt, 2001; Vaidya, Gray, Haig, Mroczek, \& Watson, 2008), we examined four complementary indices of continuity versus change: rank-order, meanlevel, individual-level, and ipsative.

\section{Rank-Order Stability}

Rank-order stability, typically assessed using correlation coefficients, reflects the extent to which members of a group maintain their individual differences over time (e.g., Roberts \& DelVecchio, 2000). The higher the correlation between reported mate preferences at two points in time, the more stable the relative ordering of individuals within the sample. To date, rankorder stability has been the most commonly reported index of standard stability, with five of the six aforementioned studies focusing primarily on test-retest correlations. But only one of these studies examined the rank-order stability of people's mate standards over more than five months (Shackelford et al., 2005), and, due to methodological limitations, does not provide reliable 
estimates of mate preferences' long-term consistency. Nevertheless, to the extent that mate preferences exhibit "trait-like" stability, we would expect the present research to yield rank-order coefficients comparable in magnitude to those of personality characteristics over several years, somewhere in the .55 to .75 range (Roberts \& DelVecchio, 2000; Specht, Egloff, \& Schmukle, 2011). Also of interest is the pattern of stability coefficients over time (cf. Fraley \& Roberts, 2005); to the extent that mate standards' rank-order stability is affected by individual adjustments in criteria that accumulate gradually over time, the size of the correlation between two preference ratings should decrease as the number of months between assessments increases.

\section{Mean and Individual-Level Stability}

Whereas rank-order stability depicts the amount of 'shuffling' that occurs within a sample across waves, mean-level change reflects a sample-wide shift in the average importance of a particular trait over time (Specht et al., 2011). In other words, this index addresses whether or not people's mate standards - on average - have a tendency to increase or decrease over several years. To date, Shackelford et al. (2005) are the only researchers who have explicitly examined mean-level change in people's mate criteria, and it is difficult to know what proportion of their generally null results may be due to low statistical power. Nevertheless, there is little reason to anticipate a sample-wide increase or decrease in people's mate standards over the course of our study. Although there are several factors that may lead people to alter their criteria over time, the diverse backgrounds, ages, and relationship statuses of our participants make it unlikely such changes would follow a uniform pattern. But apparent continuity at the grouplevel may mask significant individual-level effects if people change in opposite directions across time (Roberts et al., 2001; Vaidya et al., 2008). Thus, we also utilize growth curve modeling to examine individual differences in the magnitude and direction of people's change trajectories, 
which we refer to as individual-level stability. Consistent with our mean-level predictions, we did not expect the fixed effect for the slope of our growth models to be significant. We did, however, predict that the random effect for the slope would be significant, indicating meaningful individual differences in temporal stability within our sample.

\section{Ipsative Stability}

Finally, in contrast to the between-person indices discussed above (which are most akin to the level metric), measures of ipsative stability assess the intraindividual stability of a person's preferences across time (more akin to the pattern metric). Rather than showing how much any given preference changes relative to the sample, ipsative stability reflects how much the configuration of a person's set of criteria changes across waves. Ipsative stability is typically assessed via measures of profile similarity; the higher the correlation between a ranked set of attributes at two time points, the more stable a person's ratings of the relative importance of the traits. Despite evidence that the pattern of people's mate preferences may predict partnering behaviors better than the level of any particular criterion (e.g., Eastwick \& Neff, 2012; Eastwick et al., 2014), little is known about the stability of such profiles over time. Do people experience fewer, or less dramatic, shifts in the relative ordering of their preferences over time than they do in the level of the traits desired (perhaps contributing to the differing prospective validity of the two metrics)? Although Zentner (2005) revealed a respectably high correlation (.72) between the preference rankings of continuously partnered individuals over nine months, it is unknown whether comparable levels of stability will be evident in more diverse samples or to what extent standard profile correlations attenuate over longer periods of time.

\section{Factors Influencing Change in Mate Standards}


In addition to examining the baseline stability of people's mate criteria, a second key objective of our research was to identify and test potential moderators of mate preferences' temporal stability. As noted earlier, both evolutionary and social-cognitive theories of mate selection suggest that people's preferences should be sensitive to changes in their partnering circumstances and highlight conditions under which such shifts are expected to occur (Bredow, 2015). However, aside from work demonstrating short-term shifts in mate preferences (e.g., those experienced across the menstrual cycle; Wood, Kressel, Joshi, \& Louie, 2014), most forecasted moderators of change in people's criteria have not been tested. In this study, we examined four theoretically-derived factors that may moderate the stability of partner preferences (and, in turn, their predictive power in prospective studies): age, changes in perceived mate value, changes in perceived mate availability, and relationship events.

\section{Age}

To the extent that fluctuations in individuals' preferences for a romantic partner mirror those of personality traits, age may be a key variable influencing the continuity of people's standards over time. Although identity formation is a lifelong process, research has shown that some stages of development - such as emerging adulthood - are characterized by more rapid psychological maturation than others (Arnett, 2000; Caspi, Roberts, \& Shiner, 2005). Indeed, young adults tend to experience more pronounced identity development than their middle-aged counterparts, and personality stability typically increases throughout adulthood (Caspi et al., 2005; Roberts \& DelVecchio, 2000). Given that people's self-image and their schema of an ideal partner are assumed to be closely related (Fletcher et al., 1999), we might expect greater changes in self-concept to be associated with greater changes in partner criteria. As people's perceptions of themselves become clearer and more stable with age, so should their views of the 
qualities they desire in a partner. Accordingly, we hypothesized that older individuals will display more stable mate standards than younger individuals.

\section{Changes in Perceived Mate Value}

Building on evidence that people's own mate value is a principle factor contributing to between-person differences in criteria for a romantic partner (e.g., Bredow, 2015; Kenrick, Groth, Trost, \& Sadalla, 1993), a second variable likely to affect the temporal stability of people's standards is the constancy of their desirability as a mate. Although there is variability in the extent to which people's reported criteria reflect their self-appraisals (Bredow, 2015), both evolutionary and social exchange accounts of mate selection suggest that people's preferences will best aid partnering when they are calibrated to match their own overall mate value (Buss \& Barnes, 1986; Murstein, 1976). Because individuals are presumed to desire the best partner possible, but are likely to be rejected by prospects who are considerably more desirable than themselves, it is neither reproductively adaptive nor optimally rewarding for people to maintain criteria that fall notably above or below their own value. This suggests that people's mate standards should be sensitive to shifts in their own desirability as a partner, adjusting up or down to reflect their perceptions of their "value" in the market (cf., Todd \& Miller, 1999). Thus, we predicted that individuals who report greater change in their self-perceived mate value over 27 months will have less stable criteria than those with less variable self-appraisals.

\section{Changes in Perceived Mate Availability}

Whereas psychologists have generally focused on the role of proximal factors like mate value in shaping mating criteria, sociologists have long recognized an additional variable that influences partnering processes: the availability of desirable partners. When searching for a partner, people must generally select mates from among the limited number of eligible prospects 
they encounter in their day-to-day lives (Kalmijn \& Flap, 2001). This group of prospective partners - often referred to as the mating or marriage market (Lichter, McLaughlin, Kephart, \& Landry, 1992) - is largely shaped by the settings in which people spend a majority of their time. Independent of their own mate value, individuals who encounter few potential mates with desirable qualities are expected to have more difficulty partnering than those who are surrounded by more favorable prospects (Bredow, Huston, \& Glenn, 2011; Lichter et al., 1992). Accordingly, several researchers have argued that people's mate criteria should have evolved a sensitivity not only to their own mate value, but also to the supply of potential mates (Bredow, 2015; Sprecher \& Regan, 2002; Stone et al., 2007). To this end, we hypothesized that people who experience greater shifts in the perceived availability of prospective partners will display less stable mate standards than those who perceive less change in their mating markets.

\section{Relationship Events}

Finally, the stability of people's criteria for a romantic partner also may be related to the experience of significant relationship events. Given that people's mate preferences tend to partially reflect their views of their current partners (e.g., Murray, Holmes, \& Griffin, 1996), either entering or exiting a relationship may precipitate a shift in mating criteria. Indeed, newly dating individuals have been shown to adjust their standards in the beginning of the relationship to better match the attributes they believe their partner possesses (Fletcher et al., 2000; Gerlach et al., 2017). On the flip side, because breaking up with a romantic partner often leads to attempts to rationalize the event and reclaim one's sense of self (Slotter, Gardner, \& Finkel, 2010), the end of a relationship may similarly serve as a catalyst for changing one's partnering criteria. Lastly, important events or decision points within a relationship - such as a partner's infidelity or the decision to marry - may also undercut the stability of people's standards by 
altering their commitment level and/or precipitating shifts in their evaluative anchor (cf., Zentner, 2005). Thus, we hypothesized that individuals who experience a greater number of relational events over the course of the study will report less stable standards for a partner than those who experience fewer relationship transitions.

\section{Gender}

A well-versed reader of the mate preference literature might note that gender $-\mathrm{a}$ factor almost ubiquitously employed to account for interindividual variation in reported criteria - is not among our hypothesized moderators of mate standards' temporal stability. Although men and women's tendency to differentially value certain attributes in a partner (e.g., attractiveness vs. status) could conceivably lead to gender differences in the stability of these traits, it is unclear what form these differences would take. Moreover, given that differences between men and women's criteria tend to be minimal in long-term partnering contexts (Kenrick et al., 1993), we did not expect the stability of these preferences to differ by gender.

\section{Study Overview}

In summary, the present research sought to systematically examine the baseline stability of individuals' mate standards over 27 months and to identify factors that influence this stability. Using four waves of survey data collected at nine-month intervals from a sample of initially unmarried individuals, we investigated patterns of continuity and change in people's mate standards using four different indices - rank-order, mean-level, individual-level, and ipsative. We further examined the hypotheses that individuals who were younger, those who perceived greater changes in their mate value and mate availability, and those who experienced more relationship events would evince less stable standards for a partner than participants who were older or who underwent less contextual or relational change. 


\section{Method}

\section{Participants}

Participants in our study were initially unmarried adults recruited from a variety of settings, including university courses, community and professional organizations, social media websites, and Internet marketplaces (e.g., MTurk, Craigslist). At baseline, 805 individuals completed the survey and about two-thirds of these individuals opted to receive an invitation to the follow-up studies ( $\mathrm{n}=547)$. Altogether, 453 participants completed at least one of the three follow-up surveys (82.8\% of those contacted); 76 provided two waves of data (16.8\%), 92 provided three waves (20.3\%), and 285 provided four waves (62.9\%). To maintain continuity in our sample across both time and the different indices of stability, the present research was limited to the 285 participants ( 205 women, 79 men) who completed all four waves of the study. Participants ranged in age from 18 to $66(M=30.52, S D=10.82)$ at Time $1(\mathrm{~T} 1)$ and the sample was $73.9 \%$ Caucasian, 9.5\% Hispanic, 6.7\% Asian, 6.3\% Black, and 3.6\% Middle Eastern or mixed ethnicity. A majority of participants identified as heterosexual (95.1\%). Although only $21.4 \%$ of participants were recruited from university courses, approximately $43 \%$ of our sample were full- or part-time students and $86.3 \%$ of non-students held a Bachelor's degree or higher. At T1, most participants were never-married (80.7\%) and 52.6\% were involved in a romantic relationship. By Time 4, 34 participants had married (11.9\%) and 151 were otherwise romantically involved (53\%).

Selectivity analyses revealed that participants who completed all four waves of the study (i.e., the current sample) were older $(d=.21)$, more highly educated $(d=.42)$, and more likely to be white $(d=.24)$ than those who participated in three or fewer waves. Included participants also reported lower standards for attractiveness/vitality $(d=.29)$ and status/resources $(d=.22)$ at 
T1 than did those with less data. The two groups did not differ with respect to any other demographic characteristics (e.g., gender, marital history, relationship status) or measures of interest (e.g., mate value, mate availability). Overall, although our sample is not a fully random subset of the original pool of participants, the existing differences tended to be small in magnitude and our results were substantively identical when education, ethnicity, and age were included as covariates. Moreover, our detected patterns of stability and change remained robust when 'parallel' analyses were run using the full sample (see supplemental materials), suggesting the influence of selective attrition on our results was minimal.

\section{Procedure}

At each time point, respondents completed an online questionnaire assessing, among other things, their mate standards and dating/relationship experiences. In exchange for participating, T1 respondents received extra credit in a university course, the chance to win a $\$ 40.00$ gift card, or a small monetary reward (MTurk participants). Individuals who expressed interest in the follow-up surveys were then contacted by email approximately 9 months (T2), 18

months (T3), and 27 months (T4) after the initial study. ${ }^{1}$ Participants received $\$ 7.00, \$ 10.00$, and \$12.00 gift cards for partaking in the first, second, and third follow-ups, respectively.

\section{Measures}

Mate standards. Participants' criteria for a partner were assessed at each time point using 15 characteristics adapted from past work on the attributes people generally seek in a longterm mate (e.g., Buss, 2003; Fletcher et al., 1999). These traits were selected to represent three specific dimensions of mate preferences: physical attractiveness/vitality (e.g., good-looking and sexy, healthy and fit body), status/resources (e.g., well-educated, financially stable), and warmth/trustworthiness (e.g., kind and understanding, honest and trustworthy). Using a scale 
from 0 (not at all) to 10 (extremely), participants indicated the minimum level of each trait a prospect would need to possess to be considered an acceptable marriage partner. As expected, principle components analyses revealed a three factor solution where each characteristic loaded primarily on the dimension it was intended to reflect at each time point. The items representing each factor were averaged to create indices of participants' standards for attractiveness/vitality (4 items; Cronbach's $\alpha \mathrm{s}=.74-.78)$, status/resources (5 items; $\alpha \mathrm{s}=.83-.86$ ), and warmth/trustworthiness ( 6 items; $\alpha \mathrm{s}=.81-.83)$ at each time.

Changes in perceived mate value. Participants' perception of their own desirability as a partner was assessed using four items at each wave of measurement. First, individuals indicated their current desirability as a marriage partner both overall $\left(1=I^{\prime}\right.$ ' make a bad marriage partner, $10=I$ 'd be a great catch $)$ and relative to other same-sex singles in their area $(1=$ much less desirable, 7 = much more desirable). Participants also responded to the statements "Once they got to know me, most men/women would consider me a desirable partner in a long-term relationship" and "I have more to offer as a romantic partner than most men/women my age" (1 = strongly disagree, 7 = strongly agree). Items were standardized and averaged to create an index of participants' perceived mate value $(\alpha \mathrm{s}=.76-.82)$. To estimate change in participants' perceptions of their own mate value over the study, we used two different approaches that correspond to the nature of change captured by our stability indices. For analyses including directional indices of change in mate preferences (i.e., mean-level and individual-level) we used a residualized change index computed by regressing T4 mate value on T1 mate value and saving the residuals, such that higher scores reflect a more positive change in mate value (e.g., Roberts, O’Donnell, \& Robins, 2004). For analyses involving indices that reflect overall variability rather than change in a particular direction (i.e., rank-order and ipsative), we quantified mate value 
change using the standard error of the estimate (SEE), which estimates the extent to which an individual's mate value ratings deviate from the regression line at each time point. This approach has been used successfully in past research to capture fluctuations in a construct that are independent of the direction of change and avoids the issues of non-independence associated with absolute difference scores (e.g., Arriaga, Reed, Goodfriend, \& Agnew, 2006; Whitton, Rhoades, \& Whisman, 2014).

Changes in perceived mate availability. At each wave, mate availability was assessed using four items measuring participants' perception of the quantity and quality of potential partners in their social milieu. For three items, participants used a 7-point scale to indicate their agreement with the following statements: "There are a lot of single men/women around my age in my community," "I rarely encounter desirable men/women who are available for a long-term relationship," and "In general, there are quite a few men/women available who I could at least potentially pursue for a long-term relationship". Participants also rated the overall availability of single men/women who would make good marriage partners $(1=$ very few available, $7=$ more than enough available). These items were standardized and averaged to create a measure of the perceived availability of potential partners $(\alpha \mathrm{s}=.78-.80)$. As with mate value change, we assessed changes in perceived mate availability using both (a) residualized change scores derived from regressing T4 mate availability on T1 mate availability (where higher scores reflect a more positive change in mate availability) and (b) SEE scores reflecting the standard deviation of each participant's scores around the slope line.

Relationship events. At each follow-up, participants indicated whether they had experienced any of the following over the last 9 months: began a new romantic relationship, got engaged, got married, broke up with a romantic partner, got divorced, or discovered a partner's 
infidelity. An index of positive relationship events was created by assigning participants one point for each positive event they experienced from T1-T4, including forming a new relationship, getting engaged, and getting married (observed range: 0-4). Negative relationship events were quantified as the number of negative events participants experienced from T1-T4, including break-ups, divorce, and partner infidelity (observed range: 0-6).

\section{Analytic Strategy}

Measurement and structural invariance. As a prerequisite to further analysis of stability and change, we first conducted tests of measurement invariance to ensure that the psychometric properties of our mate standard measures were consistent over time and thus could be meaningfully compared. Specifically, we used confirmatory factor analyses to evaluate three nested models testing the tenability of (a) configural invariance (same items assess each construct over time), (b) metric invariance (equivalent item loadings across time), and (c) scalar invariance (equivalent intercepts across time). The baseline, configural model included 12 factors (one for each standard dimension at each time point) and allowed correlations among factor variances as well as residual variances for the same item at different waves (McArdle, 2009). Model fit was considered adequate if the comparative fit index (CFI) was above .90, the root-mean-square error of approximation (RMSEA) was below .06, and the standardized rootmean-square residual (SRMR) was below .08 (Hu \& Bentler, 1999; Kline, 2005). A nonsignificant chi-square change between the configural and metric models and the metric and scalar models indicates metric and scalar invariance, respectively. Assuming scalar invariance is established, a more stringent test of structural invariance can then be conducted by comparing the scalar model to a model in which the factor variances and covariances are also constrained to be equal over time. 
Rank-order stability. Rank-order stability was assessed using the Pearson productmoment correlations between waves. To examine whether the size of the stability coefficients decreased as the duration between waves increased, a series of independent and non-independent correlation difference tests also were conducted (Weaver \& Wuensch, 2013). Finally, to test our hypothesized moderators, we ran a series of moderated regression analyses for each standard dimension in which T4 standards were regressed upon T1 standards, the target moderator, and the interaction between the two.

Mean-level stability. Mean-level changes on the three standard subscales were estimated using repeated measures analysis of variance (ANOVA). To examine the influence of the hypothesized moderators on mean-level stability, a series of hierarchical regression analyses were run in which T4 mate standards were regressed on T1 mate standards (Step 1) and the target moderator (Step 2). Significant results at Step 2 indicate that the target moderator predicts T4 standard scores beyond T1 standard scores, and thus influences mate standard's mean-level stability (Vaidya, Gray, Haig, \& Watson, 2002).

Individual-level stability. To examine individual-level stability, we conducted multilevel modeling procedures using maximum likelihood (ML) estimation. Our first step was to determine the best-fitting model for individual-level change by testing both a linear and quadratic unconditional model; because four time points is considered insufficient for fitting higher-order models than quadratic (Singer \& Willet, 2003), cubic models were not tested. All models were fit using an unstructured residual covariance matrix. At the first level of analysis, each participant's score on a given standard subscale (e.g., attractiveness/vitality) was modeled as a function of linear or quadratic time in months and took the following form:

$$
\text { Standards }_{i t}=\beta_{0 i}+\beta_{1 i}\left(\text { Months }_{i t}\right)\left[+\beta_{2 i}\left(\text { Months }^{2}{ }_{i t}\right)\right]+e_{i t} .
$$


At Level 2, we originally tested for significant variability in both the linear and quadratic slopes; however, because the random coefficients for the quadratic slope were nonsignificant and added unnecessary parameters to the models, the quadratic effects were modeled as fixed prior to testing the difference in fit between our linear and quadratic models (using the chi-square test of deviance; Raudenbush \& Bryk, 2002).

After selecting the best fitting model for each standard subscale, we examined the influence of our hypothesized moderators on the linear rate of change from T1 to T4. Thus, for the conditional growth curve models, the Level 1 equation was specified to reflect the appropriate shape of change and the Level 2 equations took the following form:

$$
\begin{aligned}
& \beta_{0 i}=\gamma_{00}+\gamma_{01}\left(\text { Moderator }_{i}\right)+u_{0 i}, \\
& \beta_{1 i}=\gamma_{10}+\gamma_{11}\left(\text { Moderator }_{i}\right)+u_{1 i}, \\
& \beta_{2 i}=\gamma_{20} .
\end{aligned}
$$

Gender was dummy coded $(0=$ male, $1=$ female $)$ and all continuous moderators were grand-mean centered so that coefficients reflect the average trajectory across individuals.

Finally, to explore the direction of potential links between individuals' perceptions of their own mate value or mate availability and their criteria for a partner, we ran a series of crosslagged analyses. For each variable, we estimated a total of 6 time-lagged growth curve models three in which perceived mate value or mate availability predicted subsequent mate standards on each dimension and three in which reported standards predicted subsequent perceptions of mate value or mate availability. After determining the appropriate Level 1 models, the Level 2 models were specified as follows:

$$
\begin{aligned}
& \beta_{0 i}=\gamma_{00}+\gamma_{01}\left(\text { Lagged Predictor }_{i}\right)+u_{0 i}, \\
& \beta_{1 i}=\gamma_{10}+u_{1 i},
\end{aligned}
$$




$$
\left[\beta_{2 i}=\gamma_{20}\right]
$$

Ipsative stability. Profile stability coefficients were estimated by conducting withinperson correlations between each individual's scores on the 15 standards at each combination of time points. The T1-T4 correlation coefficient was Fisher $z$ transformed to create a measure of ipsative stability across the 27-month study. Linear regressions were used to examine the associations between ipsative stability and the hypothesized moderators.

\section{Results}

Descriptive statistics for all study variables are provided in Table 1. Consistent with evolutionary theory and past research on mate preferences (e.g., Buss, 2003), women reported higher standards for warmth/trustworthiness $(t(282)=-4.28, p<.001, d=.46)$ and status/ resources $(t(282)=-7.60, p<.001, d=.86)$ than did men, whereas men reported marginally higher standards for attractiveness/vitality than women $(t(282)=1.73, p=.08, d=.14)$.

\section{Measurement and Structural Invariance}

Before proceeding to the main analyses, the measurement and structural invariance of our mate standard measures were tested. The configural invariance model demonstrated an adequate fit to the data $(\mathrm{CFI}=.915, \mathrm{RMSEA}=.044, \mathrm{SRMR}=.066)$ and adding the constraint of equivalent factor loadings did not significantly worsen the model fit $\left(\Delta \chi^{2}(36)=39.62, p=.312\right)$, indicating metric invariance. The metric model, in turn, did not significantly differ from the scalar (equivalent intercept) model $\left(\Delta \chi^{2}(34)=43.02, p=.138\right)$, thus establishing strong measurement invariance. Finally, comparing the scalar model to a more restrictive structural model (equivalent factor variances and covariances) also did not result in a reduction of model fit $\left(\Delta \chi^{2}(18)=20.12, p=.326\right)$, suggesting high structural congruence over time. Taken together, these analyses provide strong evidence that the three factor model of mate standards holds over 
time and that our measured constructs have equivalent meaning from T1-T4, thus permitting their longitudinal comparison.

\section{Baseline Stability of Mate Standards}

Rank-order stability. As detailed in Table 2, the mate standard retest correlations were significant across all four waves. Correlations ranged from a low of .51 to a high of .73, indicating a level of rank-order stability comparable to that of personality characteristics over several years (e.g., Specht et al., 2011). As expected, the strength of the correlations generally decreased in magnitude as the time between assessments increased. Although there was not a significant change in the size of the stability coefficients when the testing duration increased from 9 to 18 months, both the 9-month and 18-month correlations were significantly stronger than the 27-month correlations for standards pertaining to attractiveness/vitality $\left(Z_{18}=2.07, p<\right.$ $\left..05 ; Z_{27}=2.28, p<.05\right)$ and at least marginally stronger for status/resources $\left(Z_{18}=1.97, p<.05\right.$; $\left.Z_{27}=1.73, p<.10\right)$. A similar pattern was observed for warmth/trustworthiness, but did not reach conventional levels of significance. ${ }^{2}$

Mean-level stability. Table 3 provides the means and standard deviations for mate standards at each assessment, as well as an overall F-test for change across the four time points. Contrary to our expectation that mate standards would not display a consistent pattern of meanlevel change over time, significant increases were found between $\mathrm{T} 1$ and $\mathrm{T} 4$ for all three subscales: attractiveness/vitality $(d=.28)$, status/resources $(d=.23)$, and warmth/trustworthiness $(d=.35)$. Bonferroni post hoc tests revealed that although T1 mate standards were significantly lower than T2, T3, and T4 standards for all three trait dimensions $(p s<.01)$, there were no significant mean-level changes between T2 and T4. Thus, the T1-T4 mean-level changes appear to be driven by an increase in standards occurring between the first two waves of the study. 
Given that our subsample reported lower T1 standards for attractiveness/vitality and status/resources than did those with incomplete data, we explored whether unexpected shifts in these measures might reflect regression to the mean. Supporting this idea, analyses comparing the $\mathrm{T} 1$ attractiveness/vitality and status/resources means for individuals with missing data to the T2-T4 means of our subsample on these measures revealed no significant differences ( $p$ s ranged from .30 to .96). Regression to the mean could not, however, account for the mean-level change in warmth/trustworthiness criteria, a point we return to in the discussion.

Individual-level stability. Building on our mean-level analyses, we next used growth curve modeling to test our prediction that - irrespective of sample-wide trends - there would be significant variability in people's individual change trajectories. First, we estimated an interceptonly model of mate standards to examine the ratio of between-person and within-person variance. These analyses revealed intraclass correlations of .62 for attractiveness/vitality, .67 for status/resources, and .53 for warmth/trustworthiness, indicating that $62 \%, 67 \%$, and $53 \%$ of the total variability in standards for the dimension was between-person variation. After verifying that there was intraindividual variation in mate standards to model, we compared the unconditional linear and quadratic models for each dimension. As we would expect, the fixed effects in Table 4 are consistent with our mean-level findings. All three fixed effect coefficients were significant for each trait dimension, and in each case the best fitting model was characterized by both linear and quadratic change (Model 2). Inspection of the random effects reveals that, as hypothesized, the intercept and linear slope variances also were significant for each dimension. Thus, although the curvature of individuals' change trajectories did not vary, there was significant variability in the extent to which people's criteria increased (or decreased) linearly over the study. 
Ipsative stability. As shown in Table 5, the mean level of profile consistency from T1 to T4 was $.60(S D=.23)$, with stability coefficients ranging from -.45 to .94 . Although a majority of individuals had mate preference profiles that were highly consistent over the 27 months (50\% had consistency scores between .65 and .94 ), there was some variability $-15.4 \%$ had correlations under .40 and $2.5 \%$ were actually negative. Unlike rank-order stability, which tended to decrease over time, ipsative stability remained quite consistent across waves, showing no significant decline as duration increased from 9 to 27 months.

\section{Moderators of Stability and Change}

Age. Our first moderation hypothesis was that older individuals would demonstrate more stable standards than their younger counterparts. Overall, we found minimal evidence for age as a moderator of between-person indices of stability (Table 6, Row 1); age did not influence the mean-level or individual-level stability of standards for any of the three dimensions, and only one marginal interaction was found for rank-order stability, such that older individuals demonstrated greater rank-order stability in their criteria for status/resources than younger individuals $(b=.83(.16), t(281)=5.38, p<.001$ at age 41 vs. $b=.71(.08), t(281)=8.56, p<$ .001 at age 20 ). In contrast, age was positively and significantly related to individuals' ipsative stability across the 27 months. Consistent with our expectations, older individuals had more stable profiles over the course of the study than did younger individuals.

Changes in perceived mate value. Second, we predicted that individuals who reported greater changes in self-perceived mate value would exhibit less stable criteria than those with more consistent self-appraisals. In contrast to age, changes in participants' perceived mate value significantly moderated the mean- and individual-level stability of people's standards for all three dimensions, but were unrelated to the rank-order and ipsative stability of people's criteria 
(Table 6, Row 2). As expected, individuals who reported greater increases in perceived mate value over the course of the study displayed greater mean-level and linear increases in mate standards over this period (see Figure 1$).^{3}$

Consistent with theoretical assumptions that shifts in mate value should drive changes in reported criteria, rather than vice versa, perceived mate value positively and significantly predicted successive standard ratings on all three trait dimensions, $\gamma=0.14, t(850)=2.71, p=$ .007 for attractiveness/vitality, $\gamma=0.13, t(837)=2.63, p=.009$ for status/resources, and $\gamma=0.09$, $t(849)=2.27, p=.024$ for warmth/trustworthiness. None of the models using lagged standards to predict mate value perceptions were significant $(p s>.42)$. There was, however, a linear effect of time on perceived mate value; the average participant viewed his or her mate value as increasing slightly over the study $(\gamma=0.003, t(285)=2.16, p=.03)$, and this slope varied significantly among participants $(z=3.27, p=.001)$.

Changes in perceived mate availability. Similar to mate value, we expected people who experienced greater shifts in perceived mate availability to display less stable criteria than those with more stable mating markets. However, changes in perceived mate availability did not significantly moderate the ipsative, mean-level, or individual-level stability of people's standards (regardless of trait dimension), and only one significant rank-order interaction was found (Table 6, Row 3). Consistent with our prediction, individuals who reported more change in mate availability demonstrated lower rank-order stability for warmth/trustworthiness standards $(b=$ $.38(.05), t(282)=8.26, p<.001$ at $+1 S D)$ than those with less variable markets $(b=.57(.06)$, $t(282)=9.80, p<.001$ at $-1 S D)$. Nevertheless, aside from this isolated effect, experiencing greater changes in the perceived availability of eligible partners did not predict holding less stable mate criteria over the course of the study. Notably, these null effects were not due to a 
lack of change in mate availability from T1 to T4; growth curve analyses revealed that, on average, perceived mate availability decreased linearly over the 27 -month study $(\gamma=-0.01$, $t(285)=-2.59, p=.01)$ and that there was significant variability in this slope $(z=2.72, p=$ $.007) .{ }^{4}$ Interestingly, we did find one cross-lagged effect of mate availability on mate standards, such that individuals who reported greater access to desirable partners at one point in time tended to report higher standards for attractiveness/vitality at the subsequent wave $(\gamma=0.07, t(850)=$ 2.34, $p=.019)$; none of the other five cross-lagged models were significant.

Relationship events. Our final hypothesis was that people who experienced a greater number of relational events over the study would evince less stable mate standards than people with fewer relationship transitions. Although the number of positive relationship events (e.g., new relationships; getting engaged) experienced did not influence the rank-order stability of people's standards, moderation effects were found for each of the other stability indices (Table 6, Row 4). As expected, individuals who experienced more positive events between T1 and T4 displayed greater increases in their standards for attractiveness/vitality over this period than those who experienced fewer positive events. This was not true, however, for standards related to status/resources or warmth/trustworthiness. A similar, albeit marginal, result was found for the individual-level stability of attractiveness/vitality criteria: the more positive relationship events experienced, the greater the linear increase in attractiveness/vitality standards ( 0 events: $b=$ $.006(.00), t(284)=1.75, p=.08 ; 2$ events: $b=.013(.00), t(284)=3.92, p<.001)$. Positive events also moderated the individual-level stability of people's warmth/trustworthiness criteria, such that warmth/trustworthiness standards increased more steeply for those with more positive relationship events $(2$ events: $b=.014(.00), t(284)=6.94, p<.001)$ than those with fewer positive events ( 0 events: $b=.006(.00), t(284)=2.00, p=.046)$. Lastly, positive events 
moderated the ipsative stability of people's criteria; as predicted, individuals who reported a greater number of positive relationship events had less stable standard profiles from T1 to T4.

Compared to positive relationship events, the number of negative relationship events (e.g., break-ups; infidelity) reported over the 27-month period had fewer effects on standard stability (Table 6, Row 5). Experiencing more negative events did not influence the rank-order or mean-level stability of people's criteria and only one individual-level effect was found: people reporting a greater number of negative events displayed lower linear increases in their criteria for status/resources $(0$ events: $b=.014(.00), t(284)=4.84, p<.001 ; 2$ events: $b=.005(.00), t(284)=$ $1.39, p=.17)$. As with positive events, negative relationship events also predicted the amount of ipsative change that occurred, such that individuals who reported more negative events reported less stable patterns of mate criteria from T1 to T4. However, when the effects of positive and negative events on ipsative stability were considered simultaneously, only the number of positive events remained significant $(B=-.07, t(280)=-3.38, p=.001$; negative events: $B=-.02, t(280)$ $=-1.13, p=.26)$.

Gender. Mostly supporting our hypothesis that gender would not moderate the stability of people's mate standards, only one significant gender effect was detected. Specifically, there was a gender difference in the mean-level stability of standards for status/resources, such that women reported greater increases in their criteria for status/resources from T1 to T4 than did men (Table 6, Row 6). We also explored the possibility that gender might influence the nature or magnitude of the effects of our four hypothesized moderators on standard stability, but found little evidence that this was the case; out of 50 moderation analyses run, only two were significant, which did not exceed chance levels.

\section{Discussion}


Although research on mate preferences has been built on the assumption that the criteria people report at one point in time should predict their future partnering behavior, this study is the first to systematically examine the stability of people's mate standards over time. Using four distinct indices to track stability and change in criteria over 27 months, our research sheds new light on the complexity of utilizing previously stated preferences to understand future partnering behaviors. On the one hand, our results are promising, suggesting that people's standards for a long-term partner are, on average, relatively stable over several years. On the other hand, there were notable between-person and person-centered changes in mate standards over the duration of the study, and we identified several contexts where the stability - and, by extension, predictive validity - of people's mate criteria may be lower. These patterns and their potential implications for mate selection processes are discussed below.

\section{Baseline Stability of Mate Standards}

A central objective of the present study was to examine the average, or baseline, stability of originally unmarried individuals' mate criteria over several years. Overall, despite some variability among metrics, our results provide convergent evidence that reported mate standards are generally quite stable across 27 months. Indeed, although our T1-T4 rank-order stability coefficients were smaller than those Fletcher et al. (1999) obtained over a three-week period (.51-.63 vs. .75-.86), they were surprisingly comparable to Eastwick and Finkel's (2008) 1month coefficients $(.52-.68)$ and within the range typical for personality traits over several years (Roberts \& DelVecchio, 2000; Specht et al., 2001). A comparable picture of continuity emerged for mate standards' ipsative stability: over $80 \%$ of participants displayed moderate to high profile correlations over time $\left(r_{q 14}>.40\right)$, and very few $(<2.5 \%)$ dramatically reconfigured their image of a desirable partner over the course of the study. Despite greater demographic and relational 
diversity, our sample's 27-month median profile correlation of .65 was only slightly lower than Zentner's (2005) 9-month median of .72. However, whereas rank-order stability tended to decrease as the interval between assessments increased - as would be expected if changes in relative ordering result from a gradual accumulation of individuals' unique mating adaptations the ipsative stability of people's criteria showed minimal change over time. This difference is interesting and suggests that intraindividual changes in the pattern of traits people desire may not accrue in the same manner as between-person shifts, resulting in greater consistency of ipsative profiles over time. This pattern is consistent with the differential predictive validity of level versus pattern metrics over a two- to three-year period (e.g., Eastwick \& Neff, 2012) and lends credence to the possibility that lower temporal stability could contribute to the lower predictive validity of the level metric in prospective studies.

Although still supporting a pattern of fairly high baseline stability, our findings regarding mate standards' mean- and individual-level stability were somewhat unexpected. Despite anticipating variability in individuals' change trajectories, we did not expect to observe samplewide changes in the stringency of participants' preferences over time. Nevertheless, our sample demonstrated a significant increase in criteria for all three trait dimensions over 27 months, primarily between the first two waves of the study. Inspection of this pattern indicated that although the shape of this quadratic trajectory did not vary among participants, there was significant variability in the rate of (linear) increase over time. Thus, controlling for a general tendency for people to increase their standards between the original study and the 9-month follow-up, participants differed significantly in the extent to which their criteria increased or decreased over the study. Interestingly, analyses of our subsample compared to people excluded due to incomplete data revealed that regression to the mean was a plausible explanation for 
observed increases in attractiveness/vitality and status/resource standards between T1 and T2, but could not explain the jump in criteria for warmth/trustworthiness. Pending replication, these results could suggest there is something about participating in research on mate selection that leads individuals to subsequently raise their criteria for certain traits (e.g., increased salience of preferences, greater relational introspection), but this explanation remains speculative.

\section{Moderators of Stability vs. Change}

The second objective of our research was to identify and test theoretically-rooted moderators of continuity versus change in individuals' mate criteria. Although our analyses of baseline stability revealed reasonably high consistency in people's standards over time, overall stability does not imply rigidity, and both evolutionary and social psychological theories of mate selection postulate conditions under which people's mate criteria should be more or less elastic (e.g., Bredow, 2015; Campbell et al., 2001; Stone et al., 2007). Our study is the first, however, to formally test these propositions using multi-wave data. Consistent with the notion that people's standards should be sensitive to changes in their partnering circumstances (Bredow, 2015), three out of four proposed moderators predicted mate standards' temporal stability in the expected manner, including age, changes in perceived mate value, and relationship events. At the same time, no single variable moderated all four indices of stability, revealing a nuanced picture of change where certain factors uniquely influenced certain types of stability.

First, mirroring age-related trends observed in personality research (e.g., Roberts et al., 2006), our findings provide some support for the notion that people's mate criteria become more stable with age. But, interestingly, this was primarily the case for person-centered measures of stability. Aside from marginal evidence that older individuals exhibit greater rank-order stability in their standards for status/resources, age was largely unrelated to between-person indices of 
stability. Rather, age was associated with greater intraindividual stability in reported criteria, such that older individuals experienced less change in their pattern of preferences over the study than did younger individuals. Although longitudinal research tracking the evolution of young adults' standards as they age is needed to verify our cross-sectional observations and rule out cohort effects, our work suggests that greater identity stability may make people less prone to modify the configuration of traits they desire in a partner, while minimally affecting their propensity to adjust the stringency of these criteria.

Second, consistent with past work demonstrating strong cross-sectional links between people's mate standards and their own traits (e.g., Bredow et al., 2011; Kenrick et al., 1993; Sprecher \& Regan, 2002), changes in perceived mate value were a robust predictor of mean- and individual-level standard stability. Individuals who experienced greater T1-T4 increases in their perception of their own mate value exhibited greater mean and linear increases on all three mate standard dimensions over the course of the study. In contrast, neither rank-order nor ipsative stability were associated with changes in perceived mate value, suggesting that indices capturing overall variability (versus directional change) may be less influenced by changes in mate value over time. Indeed, people who perceive an increase or decrease in their own desirability may adjust the overall stringency of their standards without necessarily altering the pattern of traits they desire. Our cross-lagged analyses support our directional interpretation of this link, showing that people's perceived mate value influenced subsequent ratings of their standards but not vice versa. Although not a substitute for future studies that test this causal assumption experimentally, these results are consistent with - and provide unique support for - theoretical propositions that level of people's mate standards should be sensitive to changing self-appraisals. 
At the same time, our results pertaining to mate availability indicate that people's criteria may not respond to all mating constraints equally. Aside from one significant interaction suggesting lower rank-order stability among people with more variable mating markets (which should be interpreted with caution due to the risk of Type II error), individuals who reported greater change in the perceived availability of desirable partners had no less stable standards than those who experienced more steady market conditions. Given that these null effects cannot be explained by a lack of change in participants' perceptions of mate availability over the study, why might mating criteria be largely impervious to this key partnering constraint? Although it is possible that people are simply not attentive to changes in mate availability the way they are to shifts in their own desirability, both qualitative accounts of the salience of mate availability among unmarried adults (e.g., Sharp \& Ganong, 2007) and our supplemental analyses suggest this is unlikely to be the case. Whereas decreases in perceived mate availability did not predict drops in reported standards, they did predict increasing pessimism regarding the attainability of these criteria. Thus, rather than implying that people are oblivious to the ramifications of their changing markets, our results may reveal an underlying reluctance to modify one's criteria in response to environmental, as opposed to intrinsic, factors. Albeit unpredicted, this pattern is consistent with work showing that people's mate preferences are more strongly related to their own traits than to the traits of available partners (Bredow, 2015; Bredow et al., 2011; Sprecher \& Regan, 2002), and implicates mate availability as a central factor affecting mate preference fulfillment.

Finally, congruent with evidence that people's mate preferences are shaped, at least in part, by their current relationship partner and experiences (Fletcher et al., 2000; Gerlach et al., 2017), we found moderate support for our prediction that individuals who experienced more 
relationship events throughout the study would have less stable standards than those with less eventful love-lives. Although relationship events were generally unrelated to the rank-order or mean-level stability of people's criteria, experiencing more positive events predicted lower ipsative and individual-level stability. Individuals who underwent a greater number of positive relational changes - including beginning a new relationship or increasing their commitment via engagement or marriage - were more likely to alter the pattern of traits they prioritized in a mate. Interestingly, this was not the case for negative relationship events once the incidence of positive events was controlled, suggesting that profile "reshuffling" may predominantly occur via coherence-maximizing processes where individuals strengthen the importance of traits that match their chosen partner and lessen the import of traits that do not (Fletcher et al., 2000; Simon \& Spiller, 2016). Experiencing a greater number of positive events also was associated with greater than average T1-T4 increases in people's criteria for attractiveness/vitality and warmth/trustworthiness, whereas experiencing more negative events suppressed increases in people's criteria, but only for status/resources. Taken together, our results suggest that the 27month stability of people's standards is more sensitive to positive than to negative relational events and beg further research addressing if and how negative events like break-ups or infidelity shape people's partnering criteria.

\section{Limitations \& Future Directions}

Despite the numerous strengths of this study - including its multi-wave longitudinal design; the use of a large, heterogeneous sample of adults; and the many contributions noted in the preceding paragraphs - we are cognizant of several limitations that we hope will be catalysts for additional work in this area. Although our research breaks new ground by examining mate standards at four time points spanning almost two-and-a-half years, future studies are needed to 
investigate standard stability over longer periods of time. Indeed, 27 months is only a fraction of the time most adults spend in the 'market', and mate criteria may continue to evolve as people enter new life stages, but these longer-term trends could not be addressed. On the flipside, our moderate retest interval of 9 months may have masked finer-tuned fluctuations in criteria that occur on a monthly, weekly, or even daily basis. For instance, if negative relationship events have less enduring effects on criteria than positive transitions, our design could have overlooked shorter-term shifts in preferences corresponding to these events. Research utilizing shorter assessment intervals (or daily diary designs) is needed to examine such possibilities.

It is also important to note that - despite using a longitudinal design - we cannot draw causal inferences regarding the role of our moderators as antecedents of changes in people's preferences. Although our ability to isolate cross-lagged effects of perceived mate value on stated criteria certainly increases our confidence in this interpretation, the structure of our data did not enable us to run parallel analyses for the link between relationship events and standards. Future research should supplement this work with experimental and event-driven designs that can better explicate the pathways underlying stability and change in people's partnering criteria. Utilizing experimental designs also would address the notorious difficulty of detecting small interaction effects using field studies (McClelland \& Judd, 1993). Although our study was sufficiently powered to test the majority of our effects, an $n$ of nearly 400 is required to achieve a power level of .80 in detecting small interaction effects in OLS regression $\left(\mathrm{f}^{2}=.02\right.$; Faul, Erdfelder, Buchner, \& Lang, 2009), which could have contributed to the relative dearth of moderation effects for rank-order stability. To the best of our knowledge, no published studies have experimentally manipulated contextual factors to see if and how they affect the stability of reported mate criteria, suggesting this is an area ripe for future investigation. 


\section{Conclusion}

So what can be concluded regarding the stability of reported mate standards - and, by extension, their likely role in mate selection processes? Is Sandra's current preference for an attractive partner likely to be steady over the next two to three years, or a transient fancy that holds little chance of influencing her later relationship behaviors? Overall, our results suggest the former, revealing moderate to high levels of baseline stability that point to mate preferences' potential utility in understanding future partnering processes. At the same time, the discovery of contextual and metric factors influencing standard stability underscores the complexity of this endeavor and highlights the need for more sophisticated studies that move beyond treating mate preferences as fixed variables. We don't need to call off the whole love affair - we need to become better acquainted with our date. 


\section{References}

Arnett, J. J. (2000). Emerging adulthood: A theory of development from the late teens through the twenties. American Psychologist, 55, 469-480. doi:10.1037/0003-066X.55.5.469

Arriaga, X. B., Reed, J. T., Goodfriend, W., \& Agnew, C. R. (2006). Relationship perceptions and persistence: Do fluctuations in perceived partner commitment undermine dating relationships? Journal of Personality and Social Psychology, 91, 1045-1065. doi:10.1037/0022-3514.91.6.1045

Bredow, C. A. (2015). Chasing Prince Charming: Partnering consequences of holding unrealistic standards for a spouse. Personal Relationships, 22, 476-501. doi:10.1111/pere.12091

Bredow, C. A., Huston, T. L., \& Glenn, N. D. (2011). Market value, quality of the pool of potential mates, and singles' confidence about marrying. Personal Relationships, 18, 3957. doi:10.1111/j.1475-6811.2010.01302.x

Buss, D. M. (2003). The evolution of desire. New York: Basic Books.

Buss, D. M., \& Barnes, M. (1986). Preferences in human mate selection. Journal of Personality and Social Psychology, 50, 559-570. doi:10.1037/0022-3514.50.3.559

Campbell, L., Simpson, J. A., Kashy, D. A., \& Fletcher, G. J. O. (2001). Ideal standards, the self, and flexibility of ideals in close relationships. Personality and Social Psychology Bulletin, 27, 447-462. doi:10.1177/0146167201274006

Caspi, A., Roberts, B. W., \& Shiner, R. L. (2005). Personality development: Stability and change. Annual Review of Psychology, 56, 453-484.

doi:10.1146/annurev.psych.55.090902.141913 
Conroy-Beam, D., \& Buss, D. M. (2016). Do mate preferences influence actual mating decisions? Evidence from computer simulations and three studies of mated couples. Journal of Personality and Social Psychology, 111, 53-66. doi:10.1037/pspi0000054

Cosmides, L., \& Tooby, J. (1992). Cognitive adaptations for social exchange. In J. H. Barkow, L. Cosmides, \& J. Tooby (Eds.), The adapted mind: Evolutionary psychology and the generation of culture (pp. 163-228). New York: Oxford University Press.

Eastwick, P. W., \& Finkel, E. J. (2008). Sex differences in mate preferences revisited: Do people know what they initially desire in a romantic partner? Journal of Personality and Social Psychology, 94, 245-264. doi:10.1037/0022-3514.94.2.245

Eastwick, P. W., Finkel, E. J., \& Eagly, A. H. (2011). When and why do ideal partner preferences affect the process of initiating and maintaining romantic relationships? Journal of Personality and Social Psychology, 101, 1012-1032. doi:10.1037/a0024062

Eastwick, P. W., Luchies, L. B., Finkel, E. J., \& Hunt, L. L. (2014). The predictive validity of ideal partner preferences: A review and meta-analysis. Psychological Bulletin, 140, 623665. doi:10.1037/a0032432

Eastwick, P. W., \& Neff, L. A. (2012). Do ideal partner preferences predict divorce? A tale of two metrics. Social Psychological and Personality Science, 3, 667-674. doi:10.1177/1948550611435941

Faul, F., Erdfelder, E., Buchner, A., \& Lang, A.-G. (2009). Statistical power analyses using G*Power 3.1: Tests for correlation and regression analyses. Behavior Research Methods, 41, 1149-1160. doi:10.3758/BRM.41.4.1149

Fletcher, G. J., O., Kerr, P. S. G., Li, N. P., \& Valentine, K. A. (2014). Predicting romantic interest and decisions in the very early stages of mate selection: standards, accuracy, and 
sex difference. Personality and Social Psychology Bulletin, 40, 540-550.

doi:10.1177/0146167213519481

Fletcher, G. J. O., Simpson, J. A., \& Thomas, G. (2000). Ideals, perceptions, and evaluations in early relationship development. Journal of Personality and Social Psychology, 79, 933940. doi:10.1037/0022-3514.79.6.933

Fletcher, G. J. O., Simpson, J. A., Thomas, G., \& Giles, L. (1999). Ideals in intimate relationships. Journal of Personality and Social Psychology, 76, 72-89. doi:10.1037/0022-3514.76.1.72

Fraley, R. C., \& Roberts, B. W. (2005). Patterns of continuity: A dynamic model for conceptualizing the stability of individual differences in psychological constructs across the life course. Psychological Review, 112, 60-74. doi:10.1037/0033-295X.112.1.60

Gangestad, S. W., Haselton, M. G., \& Buss, D. M. (2006). Evolutionary foundations of cultural variation: Evoked culture and mate preferences. Psychological Inquiry, 17, 75-95. doi:10.1207/s15327965pli1702_1

Gerlach, T. M., Arslan, R. C., Schultze, T., Reinhard, S. K., \& Penke, L. (2017). Predictive validity and adjustment of ideal partner preferences across the transition into romantic relationships. Journal of Personality and Social Psychology. Advance online publication. doi:10.1037/pspp0000170

Hill, R. (1945). Campus values in mate selection. Journal of Home Economics, 37, 554-558.

Hu, L. T., \& Bentler, P. M. (1999). Cutoff criteria for fit indexes in covariance structure analysis: Conventional criteria versus new alternatives. Structural Equation Modeling, 6, 1-55. doi:10.1080/10705519909540118 
Kalmijn, M., \& Flap, H. (2001). Assortative mating and meeting: Unintended consequences of organized settings for partner choices. Social Forces, 79, 1289-1312. doi:10.1353/sof.2001.0044

Kenrick, D. T., Groth, G. E., Trost, M. R., \& Sadalla, E. K. (1993). Integrating evolutionary and social exchange perspectives on relationships: Effects of gender, self-appraisal, and involvement level on mate selection criteria. Journal of Personality and Social Psychology, 64, 951-969. doi:10.1037/0022-3514.64.6.951

Kline, R. B. (2005). Principles and practice of structural equation modeling (2 ${ }^{\text {nd }}$ ed.). New York: Guilford Press.

Li, N. P., Yong, J. C., Tov, W., Sng, O., Fletcher, G. J. O., Valentine, K. A., Jiang, Y. F., \& Balliet, D. (2013). Mate preferences do predict attraction and choices in the early stages of mate selection. Journal of Personality and Social Psychology, 105, 757-776. doi:10.1037/a0033777

Lichter, D. T., McLaughlin, D. K., Kephart, G., \& Landry, D. J. (1992). Race and the retreat from marriage: A shortage of marriageable men? American Sociological Review, 57, 781799. doi:10.2307/2096123

McArdle, J. J. (2009). Latent variable modeling of differences and changes with longitudinal data. Annual Review of Psychology, 60, 577-605. doi:10.1146/annurev.psych.60.110707. 163612

McClelland, G. H., \& Judd, C. M. (1993). Statistical difficulties of detecting interactions and moderator effects. Psychological Bulletin, 114, 376-389. doi:10.1037/00332909.114.2.376 
Murray, S. L., Holmes, J. G., \& Griffin, D. W. (1996). The self-fulfilling nature of positive illusions in romantic relationships: Love is not blind, but prescient. Journal of Personality and Social Psychology, 71, 1155-1180. doi:10.1037/0022-3514.71.6.1155

Murstein, B. I. (1976). Who will marry whom? Theories and research in marital choice. New York: Springer.

Raudenbush, S. W., \& Bryk, A. S. (2002). Hierarchical linear models: Applications and data analysis methods. London: Sage.

Roberts, B. W., Caspi, A., \& Moffitt, T. E. (2001). The kids are alright: Growth and stability in personality development from adolescence to adulthood. Journal of Personality and Social Psychology, 81, 670-683. doi:10.1037/0022-3514.81.4.670

Roberts, B. W., \& DelVecchio, W. F. (2000). The rank-order consistency of personality traits from childhood to old age: A quantitative review of longitudinal studies. Psychological Bulletin, 126, 3-25. doi:10.1037/0033-2909.126.1.3

Roberts, B. W., O’Donnell, M., \& Robins, R. W. (2004). Goal and personality trait development in emerging adulthood. Journal of Personality and Social Psychology, 87, 541-550. doi:10.1037/0022-3514.87.4.541

Shackelford, T. K., Schmitt, D. P., \& Buss, D. M. (2005). Mate preferences of married persons in the newlywed year and three years later. Cognition and Emotion, 19, 1262-1270. doi:10.1080/02699930500215249

Sharp, E. A., \& Ganong, L. H. (2007). Raising awareness about marital expectations: Are unrealistic beliefs changed by integrative teaching? Family Relations, 49, 71-76. doi:10.1111/j.1741-3729.2000.00071.x 
Simon, D., \& Spiller, S. A. (2016). The elasticity of preferences. Psychological Science, 27, 1588-1599. doi:10.1177/0956797616666501

Singer, J. D., \& Willet, J. B. (2003). Applied longitudinal data analysis: Modeling change and event occurrence. New York, NY: Oxford University Press.

Slotter, E. B., Gardner, W. L., \& Finkel, E. J. (2010). Who am I without you? The influence of romantic breakup on the self-concept. Personality and Social Psychology Bulletin, 36, 147-160. doi:10.1177/0146167209352250

Specht, J., Egloff, B., \& Schmukle, S. C. (2011). Stability and change of personality across the life course: The impact of age and major life events on mean-level and rank-order stability of the Big Five. Journal of Personality and Social Psychology, 101, 862-882. doi:10.1037/a0024950

Sprecher, S., \& Regan, P. C. (2002). Liking some things (in some people) more than others: Partner preferences in romantic relationships and friendships. Journal of Social and Personal Relationships, 19, 463-481. doi:10.1177/0265407502019004048

Stone, E. A., Shackelford, T. K., \& Buss, D. M. (2007). Sex ratio and mate preferences: A crosscultural investigation. European Journal of Social Psychology, 37, 288-296. doi:10.1002/ejsp.357

Thibaut, J. W., \& Kelley, H. H. (1959). The social psychology of groups. New York: Wiley.

Todd, P. M., \& Miller, G. F. (1999). From pride and prejudice to persuasion: Satisficing in mate search. In G. Gigerenzer, P. M. Todd, \& ABC Research Group (Eds.), Simple heuristics that make us smart (pp. 287-308). New York: Oxford University Press. 
Vaidya, J. G., Gray, E. K., Haig, J. R., Mroczek, D. K., \& Watson, D. (2008). Differential stability and individual growth trajectories of Big Five and affective traits during young adulthood. Journal of Personality, 76, 267-304. doi:10.1111/j.1467-6494.2007.00486.x

Vaidya, J. G., Gray, E. K, Haig, J. R., \& Watson, D. (2002). On the temporal stability of personality: Evidence for differential stability and the role of life experiences. Journal of Personality and Social Psychology, 83, 1469-1484. doi:10.1037//0022-3514.83.6.1469

Weaver, B., \& Wuensch, K. L. (2013). SPSS and SAS programs for comparing Pearson correlations and OLS regression coefficients. Behavior Research Methods, 45, 880-895. doi:10.3758/s13428-012-0289-7

Whitton, S. W., Rhoades, G. K., \& Whisman, M. A. (2014). Fluctuation in relationship quality over time and individual well-being: Main, mediated, and moderated effects. Personality and Social Psychology Bulletin, 40, 858-871. doi:10.1177/0146167214528988

Wood, W., Kressel, L., Joshi, P. D., \& Louie, B. (2014). Meta-analysis of menstrual cycle effects on women's mate preferences. Emotion Review, 6, 229-249. doi:10.1177/1754073914523073

Zentner, M. R. (2005). Ideal mate personality concepts and compatibility in close relationships: A longitudinal analysis. Journal of Personality and Social Psychology, 89, 242-256. doi:10.1037/0022-3514.89.2.242 


\section{Footnotes}

${ }^{1}$ The mean time between completing T1 and the first (T2), second (T3), and third (T4) follow-ups were 9.18 months $(S D=.61), 17.73$ months $(S D=.86)$ and 27.37 months $(S D=.84)$, respectively.

${ }^{2}$ When comparing the strength of the T1-T4 retest correlations across dimensions, only the difference between status/resources $(r=.63)$ and warmth/trustworthiness $(r=.51)$ was significant $(Z=1.97, p<.05)$.

${ }^{3}$ Unexpectedly, the simple linear slopes for all three mate preference dimensions were positive at one standard deviation below the mean on residualized mate value change (although only the slope for warmth/trustworthiness was significant), most likely due to the unanticipated average increase in mate standards observed in our sample. Rather than decreasing their standards, individuals one standard deviation below the mean on mate value change (who tended to report fairly small absolute decreases in mate value from T1-T4) remained the same or simply raised their standards less. Nevertheless, the standard slopes become negative at 1.5 to 2.5 SDs below the mean, demonstrating that negative changes in mate value are associated with greater mean- and individual-level instability at higher levels of negative perceived change.

${ }^{4}$ To further explore the unexpected disconnect between changes in perceived mate availability and the temporal stability of mate standards, we ran an additional multilevel model testing whether changes in mate availability moderated changes in the perceived attainability of people's standards (as opposed to changes in the actual standards themselves). The interaction between mate availability change and months was significant $(\gamma=.01, t(259)=3.71, p<.001)$, and indicated that perceived attainability increased over the course of the study for people $1 S D$ above the mean on mate availability change and decreased for those $1 S D$ below the mean. 
Table 1. Zero-Order Correlations and Descriptive Statistics for Included Variables (Data in Long Format as Used for MLM Analyses)

\begin{tabular}{|c|c|c|c|c|c|c|c|c|c|c|c|c|}
\hline & 1 & 2 & 3 & 4 & 5 & 6 & 7 & 8 & 9 & 10 & 11 & 12 \\
\hline 2. Status/Resources & $.56 * *$ & - & & & & & & & & & & \\
\hline 3. Warmth/Trustworthiness & $.54 * *$ & $.58 * *$ & - & & & & & & & & & \\
\hline 4. Months (from T1) & $.09 * *$ & $.08 * *$ & $.12 * *$ & - & & & & & & & & \\
\hline 7. Mate value $\Delta$ (Residual) & $.14 * *$ & $.09 * *$ & $.08 * *$ & .00 & .01 & -.01 & - & & & & & \\
\hline 8. Mate value $\Delta(\mathrm{SEE})$ & $-.08 * *$ & .01 & -.02 & .01 & .01 & $-.14 * *$ & $-.34 * *$ & - & & & & \\
\hline 9. Mate avail $\Delta$ (Residual) & .00 & $-.10 * *$ & $-.13 * *$ & .00 & $-.17 * *$ & $-.10 * *$ & .02 & -.06 & - & & & \\
\hline 10. Mate avail $\Delta$ (SEE) & $.07 *$ & $.09 * *$ & $.14 * *$ & .01 & $.15^{* *}$ & $-.08 *$ & .04 & $.11 * *$ & $-.15 * *$ & - & & \\
\hline$M$ & 6.78 & 7.31 & 8.30 & 14.10 & .72 & 30.52 & .00 & .46 & .00 & .85 & 1.16 & .94 \\
\hline$S D$ & 1.26 & 1.28 & .94 & 10.48 & .45 & 10.81 & .63 & .26 & 1.07 & .38 & 1.05 & 1.14 \\
\hline
\end{tabular}

${ }^{\mathrm{a}}$ Means for dichotomous variables are reported as proportions.

${ }^{+} p<.10 .{ }^{*} p<.05 . * * p<.01$. 
Table 2. Rank-Order Stability of Mate Standard Subscales

\begin{tabular}{|c|c|c|c|c|c|c|c|c|c|}
\hline & \multirow[b]{2}{*}{$r_{12}$} & \multirow[b]{2}{*}{$r_{13}$} & \multirow[b]{2}{*}{$r_{14}$} & \multirow[b]{2}{*}{$r_{23}$} & \multirow[b]{2}{*}{$r_{24}$} & \multirow[b]{2}{*}{$r_{34}$} & \multicolumn{3}{|c|}{ Means } \\
\hline & & & & & & & 9 months & 18 months & 27 months \\
\hline Attractiveness/Vitality & $\begin{array}{c}.65 * * * \\
{[.57, .71]}\end{array}$ & $\begin{array}{c}.66 * * * \\
{[.57, .73]}\end{array}$ & $\begin{array}{c}.55 * * * \\
{[.45, .64]}\end{array}$ & $\begin{array}{c}.70 * * * \\
{[.63, .76]}\end{array}$ & $\begin{array}{c}.68 * * * \\
{[.61, .74]}\end{array}$ & $\begin{array}{c}.64 * * * \\
{[.56, .72]}\end{array}$ & $.67 \mathrm{a}$ & $.67 \mathrm{a}$ & $.55_{\mathrm{b}}$ \\
\hline Status/Resources & $\begin{array}{c}.72 * * * \\
{[.64, .78]}\end{array}$ & $\begin{array}{c}.71 * * * \\
{[.64, .78]}\end{array}$ & $\begin{array}{c}.63 * * * \\
{[.54, .70]}\end{array}$ & $\begin{array}{c}.73 * * * \\
{[.67, .79]}\end{array}$ & $\begin{array}{c}.70 * * * \\
{[.62, .77]}\end{array}$ & $\begin{array}{c}.71 * * * \\
{[.64, .77]}\end{array}$ & $.72_{\mathrm{a}}$ & $.71_{\mathrm{ab}}$ & $.63 \mathrm{~b}$ \\
\hline Warmth/Trustworthiness & $\begin{array}{c}.55 * * * \\
{[.46, .64]}\end{array}$ & $\begin{array}{c}.55 * * * \\
{[.45, .64]}\end{array}$ & $\begin{array}{c}.51 * * * \\
{[.41, .60]}\end{array}$ & $\begin{array}{c}.62 * * * \\
{[.53, .70]}\end{array}$ & $\begin{array}{c}.54 * * * \\
{[.44, .62]}\end{array}$ & $\begin{array}{c}.64 * * * \\
{[.56, .70]}\end{array}$ & $.60_{\mathrm{a}}$ & $.55_{\mathrm{a}}$ & $.51_{\mathrm{a}}$ \\
\hline
\end{tabular}

Note. Bracketed numbers are values for the $95 \%$ confidence interval. Correlations with different subscripts indicate a significant difference between the coefficients at $p<.05$.

$* * * p<.001$. 
Table 3. Mean-Level Stability of Mate Standard Subscales

\begin{tabular}{|c|c|c|c|c|c|c|}
\hline & \multicolumn{4}{|c|}{$\operatorname{Mean}(S D)$} & \multirow[b]{2}{*}{$F$} & \multirow[b]{2}{*}{$\mathrm{T} 1-\mathrm{T} 4 d$} \\
\hline & $\mathrm{T} 1$ & $\mathrm{~T} 2$ & $\mathrm{~T} 3$ & $\mathrm{~T} 4$ & & \\
\hline Physical Attractiveness/Vitality & $\begin{array}{c}6.55(1.22)_{\mathrm{a}} \\
{[6.40,6.69]}\end{array}$ & $\begin{array}{c}6.88(1.27)_{b} \\
{[6.72,7.03]}\end{array}$ & $\begin{array}{c}6.78(1.26)_{b} \\
{[6.64,6.93]}\end{array}$ & $\begin{array}{c}6.90(1.26)_{b} \\
{[6.75,7.06]}\end{array}$ & $13.26 * * *$ & .28 \\
\hline Status/Resources & $\begin{array}{c}7.11(1.33)_{\mathrm{a}} \\
{[6.97,7.27]}\end{array}$ & $\begin{array}{l}7.38(1.30)_{b} \\
{[7.22,7.53]}\end{array}$ & $\begin{array}{l}7.35(1.22)_{b} \\
{[7.19,7.48]}\end{array}$ & $\begin{array}{l}7.41(1.27)_{b} \\
{[7.26,7.56]}\end{array}$ & $10.85^{* * *}$ & .23 \\
\hline Warmth/Trustworthiness & $\begin{array}{c}8.07(0.97)_{\mathrm{a}} \\
{[7.95,8.18]}\end{array}$ & $\begin{array}{l}8.40(0.94)_{b} \\
{[8.29,8.51]}\end{array}$ & $\begin{array}{l}8.35(0.93)_{b} \\
{[8.24,8.46]}\end{array}$ & $\begin{array}{l}8.40(0.90)_{b} \\
{[8.30,8.51]}\end{array}$ & $18.87 * * *$ & .35 \\
\hline
\end{tabular}

Note. Different subscripts indicate a significant difference between the coefficients at $p<.05$. Bracketed numbers are values for the $95 \%$ confidence interval.

$* * * p<.001$. 
Table 4. Individual-Level Stability of Mate Standards Subscales (Multilevel Growth Models)

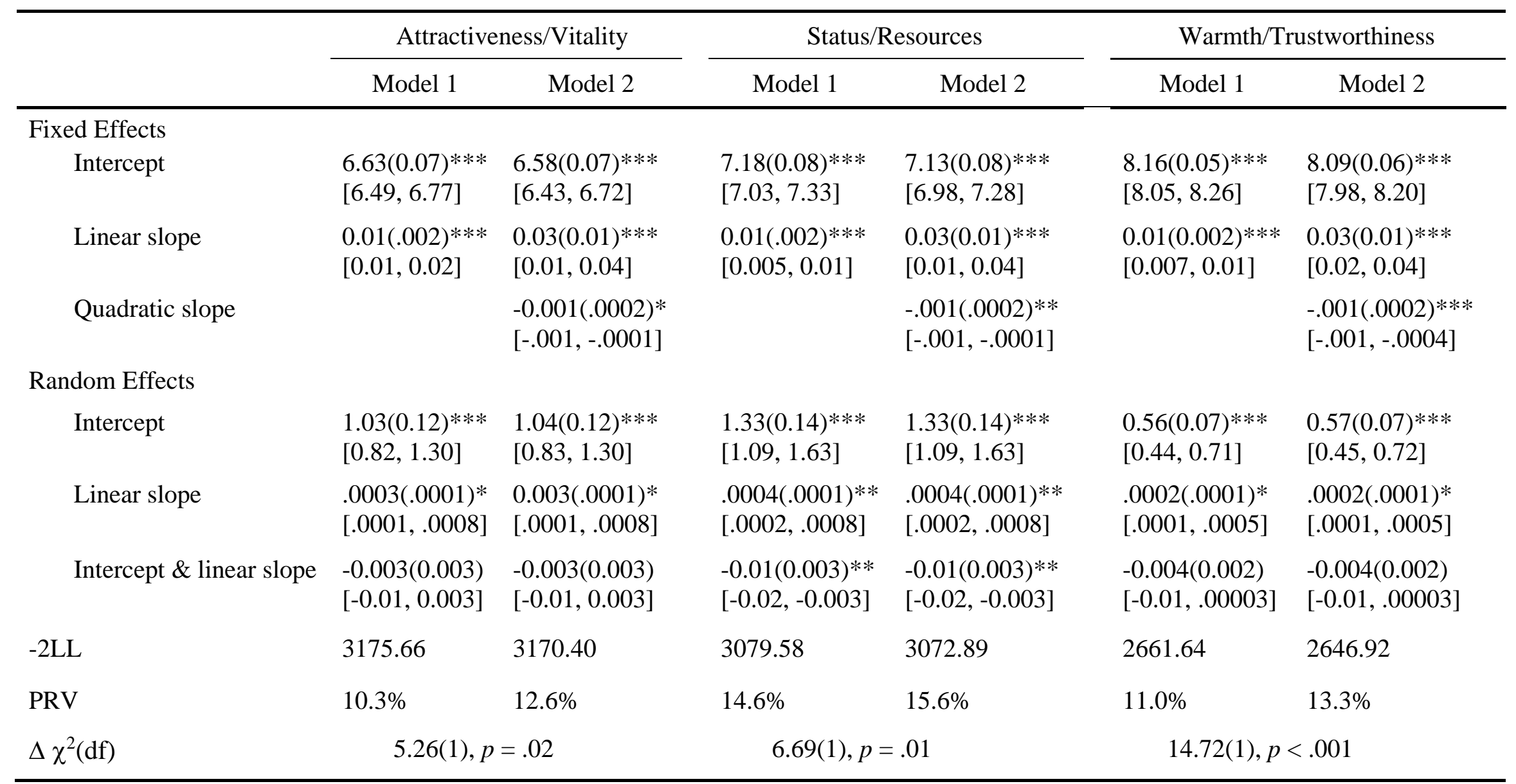

Note. Unstandardized estimates are presented with standard errors in parentheses. Model 1 is the unconditional linear growth model and Model 2 is the unconditional quadratic growth model. Bracketed numbers are values for the $95 \%$ confidence interval. PRV = proportional reduction in variance in comparison to the intercept-only model (see Raudenbush \& Bryk, 2002).

$* p<.05$. ** $p<.01 . * * * p<.001$. 
Table 5. Ipsative (Profile) Stability of Mate Standards

\begin{tabular}{lcccccc}
\hline & \multicolumn{7}{c}{ Profile Similarity } \\
\cline { 2 - 7 } & $r_{q 12}$ & $r_{q 13}$ & $r_{q 14}$ & $r_{q 23}$ & $r_{q 24}$ & $r_{q 34}$ \\
\hline Mean $(S D)$ & $.61(.23)$ & $.63(.22)$ & $.60(.23)$ & $.63(.22)$ & $.61(.21)$ & $.63(.21)$ \\
& {$[.58, .64]$} & {$[.60, .65]$} & {$[.57, .63]$} & {$[.60, .65]$} & {$[.59, .64]$} & {$[.60, .66]$} \\
Range & $-.33-.94$ & $-.19-.96$ & $-.45-.94$ & $-.29-.95$ & $-.20-.95$ & $-.28-.98$ \\
\hline
\end{tabular}

Note. Bracketed numbers are values for the $95 \%$ confidence interval. 
Table 6. Tests of Proposed Moderators on Rank-Order, Mean-Level, Individual-Level, and Ipsative Stability

\begin{tabular}{|c|c|c|c|c|c|c|c|c|c|c|}
\hline \multirow[b]{2}{*}{ Moderator } & \multicolumn{3}{|c|}{ Rank-Order } & \multicolumn{3}{|c|}{ Mean-Level } & \multicolumn{3}{|c|}{ Individual-Level } & \multirow[t]{2}{*}{ Ipsative } \\
\hline & Attract & Status & Warmth & Attract & Status & Warmth & Attract & Status & Warmth & \\
\hline Age & $.003(.01)$ & $.01(.004)^{+}$ & $.01(.01)$ & $-.01(.01)$ & $.0003(.01)$ & $.001(.004)$ & $.002(.002)$ & $.0003(.001)$ & $-.0002(.001)$ & $.01(.002)^{*}$ \\
\hline Mate Value $\Delta$ & $.11(.28)$ & $.24(.19)$ & $.25(.25)$ & $.37(.10)^{* * * *}$ & $.20(.09) *$ & $.22(.07)^{* *}$ & $.006(.002)^{* *}$ & $.006(.003) *$ & $.005(.002)^{*}$ & $-.04(.08)$ \\
\hline Mate Availability $\Delta$ & $-.11(.15)$ & $-.15(.13)$ & $-.25(.11)^{*}$ & $.05(.06)$ & $-.05(.06)$ & $-.07(.04)$ & $.001(.002)$ & $.0001(.002)$ & $-.001(.002)$ & $-.03(.06)$ \\
\hline Positive Events & $-.05(.04)$ & $-.02(.04)$ & $-.02(.04)$ & $.16(.06)^{* *}$ & $.04(.06)$ & $.05(.05)$ & $.004(.002)^{+}$ & $.0004(.002)$ & $.004(.002)^{*}$ & $-.08(.02) * * *$ \\
\hline Negative Events & $-.05(.05)$ & $.01(.04)$ & $-.07(.04)$ & $.04(.06)$ & $-.03(.05)$ & $.00(.04)$ & $.003(.002)$ & $-.004(.002)^{*}$ & $.001(.002)$ & $-.05(.02) * *$ \\
\hline Gender & $.10(.12)$ & $-.14(.10)$ & $.07(.11)$ & $-.09(.14)$ & $.42(.14) * *$ & $.14(.11)$ & $-.001(.005)$ & $-.005(.005)$ & $-.003(.004)$ & $-.01(.05)$ \\
\hline
\end{tabular}

Note. For rank-order and individual-level stability, the unstandardized estimates of the interaction terms (conducted using linear regressions and growth curve models, respectively) are presented with standard errors in parentheses. Mean-level and ipsative values reflect the unstandardized estimate and standard error of the moderator in the hierarchical linear and simple linear regressions, respectively. For meanlevel and individual-level stability, changes in mate value and mate availability were assessed using residualized change scores, whereas the standard error of estimate was used in models predicting rank-order and ipsative stability.

${ }^{+} p<.10 . * p<.05 . * * p<.01 . * * * p<.001$. 
(a)

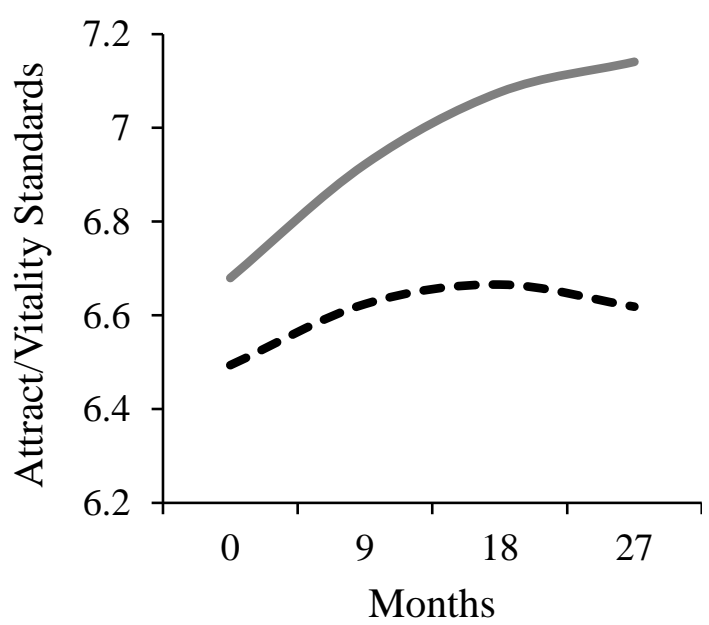

(b)



(c)

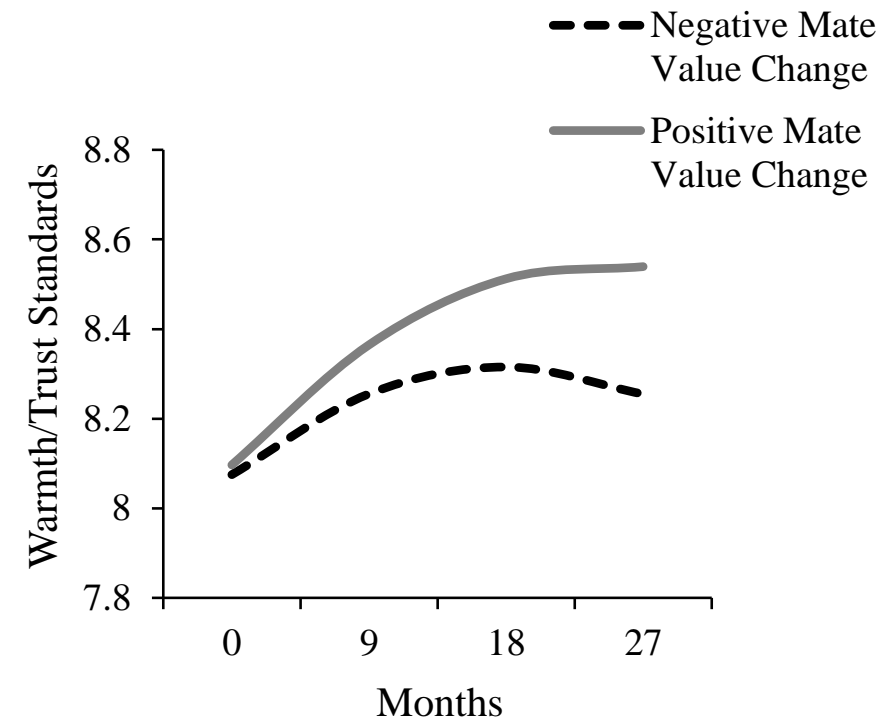

Figure 1. Mate standards for (a) attractiveness/vitality, (b) status/resources, and (c) warmth/trustworthiness as a function of time for individuals displaying more negative versus positive changes in perceived mate value. Positive and negative residualized mate value change scores are plotted at 1 standard deviation above and below the mean, respectively. 